\title{
Caracterização da farinha do sabugo de milho e sua utilização como alternativa para enriquecimento de produtos alimentícios
}

\author{
Characterization of corn cob flour and its use as an alternative for enrichment of food products \\ Caracterización de la mazorca de maíz y su uso como alternativa de enriquecimiento de productos \\ alimenticios
}

Recebido: 15/01/2022 | Revisado: 22/01/2022 | Aceito: 23/01/2022 | Publicado: 24/01/2022

Sérgio Luis Melo Viroli

ORCID: https://orcid.org/0000-0003-3982-1183 Instituto Federal do Tocantins, Brasil E-mail:viroli@ifto.edu.br

Liliane Garcia da Silva

ORCID: https://orcid.org/0000-0002-9929-0006 Instituto Federal do Tocantins, Brasil

E-mail: lilianegarcia@ifto.edu.br:

Alessandra Vespúcio Vaz

ORCID: https://orcid.org/0000-0002-9409-8031 Instituto Federal do Tocantins, Brasil

E-mail: alevvaz@ifto.edu.br

Sérgio Guimarães Viroli

ORCID: https://orcid.org/0000-0002-6558-5391

Universidade Federal do Tocantins, Brasil E-mail: sergio.viroli@mail.uft.edu.br

Nelson Pereira Carvalho

ORCID: https://orcid.org/0000-0002-7637-1292 Instituto Federal do Tocantins, Brasil

E-mail: nelson.pereira.carvalh@gmail.com

Henrique Avelino Duarte

ORCID: https://orcid.org/0000-0003-2331-5171 Instituto Federal do Tocantins, Brasil

E-mail: henrique.duarte@estudante.Ifto.edu.br

Alex da Silva Sousa

ORCID: https://orcid.org/0000-0002-1679-7267 Instituto Federal do Tocantins, Brasil

E-mail: alex.sousa4@estudante.ifto.edu.br

Lucas Torres Leite

ORCID: https://orcid.org/0000-0003-0621-3480

Universidade Federal do Tocantins, Brasil

E-email:Itorresleiteh@gmail.com

Cláudia Veloso

ORCID: https://orcid.org/0000-0002-0880-8659 Instituto Federal do Tocantins, Brasil

E-mail: claudiav@ifto.edu.br

Naylon Barroso Gomes

ORCID: https://orcid.org/0000-0002-7014-1461 Instituto Federal do Tocantins, Brasil E-mail: naylon.gomes@ifto.edu.br

Fernanda Alves Costa

ORCID: https://orcid.org/0000-0002-0889-725X Instituto Federal do Tocantins, Brasil

E-mail: fernandaalves@ifto.edu.br

Paulo Victor Gomes Sales

ORCID: https://orcid.org/0000-0002-4696-2737

Instituto Federal do Tocantins, Brasil

E-mail: paulosales@ifto.edu.br

\section{Resumo}

A farinha de sabugo de milho é constituída basicamente por hemicelulose, celulose, lignina, proteínas, açúcares simples, lipídeos, amido e água. O seu baixo custo favorece a produção de alimentos acessíveis, proporcionando à população acesso a esses com custos atrativos e competitivos, aliado com alto valor nutritivo essenciais e funcionais. Nesse sentido, o presente estudo teve como objetivo produzir e caracterizar uma farinha de sabugo de milho como alternativa de aplicabilidade no preparo ou enriquecimento de produtos alimentícios. Foram realizadas análises para 
determinação das propriedades funcionais e composição centesimal. Os valores médios obtidos foram: 0,49\% (ácido fítico), $0,03 \%$ (ácido oxálico), 2,36\% (capacidade de retenção de água), 72,82\% (carboidratos), 1,82\% (cinzas), 8,91\% (fibras), 5,0\% (índice de absorção de água), 1,32\% (lipídios), 6,37\% (potencial hidrogeniônico), 2,37\% (proteínas) e $4,36 \%$ (umidade). Os resultados físico-químicos da farinha do sabugo de milho demostram baixo valor para umidade, altos valores de fibra e cinzas quando comparados com as farinhas convencionais como: trigo, milho e mandioca, nessa perspectiva esta farinha pode apresentar potencial segurança no consumo humano. Quanto ao processo de produção da farinha do sabugo de milho, os resultados microbiológicos atenderam a legislação vigente demostrando aptidão para o consumo. A farinha de sabugo de milho produzida e analisada tem grande prisma para ser incorporada ou utilizada para enriquecer alimentos, pois contribui para um benefício fisiológico devido ao seu teor de Fibras e baixos teores de Ácidos Oxálicos e Fítico, além de minimizar e mitigar os impactos da disposição inadequada se este for disposto no ambiente sem o manejo apropriado.

Palavras-chave: Agroindustrial; Desperdício; Fibras; Reaproveitamento, Sustentabilidade.

\begin{abstract}
Corn cob flour is basically made up of hemicellulose, cellulose, lignin, proteins, simple sugars, lipids, starch and water. Its low cost favors the production of affordable food, providing the population with access to these at attractive and competitive costs, combined with essential and functional high nutritional value. In this sense, the present study aimed to produce and characterize a corn cob flour as an alternative of applicability in the preparation or enrichment of food products. Analyzes were performed to determine the functional properties and proximate composition. The average values obtained were: $0.49 \%$ (phytic acid), $0.03 \%$ (oxalic acid), $2.36 \%$ (water holding capacity), $72.82 \%$ (carbohydrates), $1.82 \%$ (ash ), 8.91\% (fibers), 5.0\% (water absorption index), $1.32 \%$ (lipids), 6.37\% (hydrogenonic potential), $2.37 \%$ (proteins) and $4.36 \%$ (moisture). The physicochemical results of corn cob flour show low value for moisture, high fiber and ash values when compared with conventional flours such as wheat, corn and cassava, in this perspective this flour may have potential safety in human consumption. As for the corn cob flour production process, the microbiological results met the current legislation, demonstrating suitability for consumption. The corn cob flour produced and analyzed has a great prism to be incorporated or used to enrich foods, as it contributes to a physiological benefit due to its fiber content and low levels of Oxalic and Phytic Acids, in addition to minimizing and mitigating the impacts of inappropriate disposal if it is disposed of in the environment without proper management.
\end{abstract}

Keywords: Agroindustrial; Waste; Fibers; Reuse; Sustainability.

\title{
Resumen
}

La harina de mazorca de maíz se compone básicamente de hemicelulosa, celulosa, lignina, proteínas, azúcares simples, lípidos, almidón y agua. Su bajo costo favorece la producción de alimentos a precios accesibles, facilitando el acceso de la población a estos a costos atractivos y competitivos, combinados con alimentos esenciales y funcionales de alto valor nutritivo. En ese sentido, el presente estudio tuvo como objetivo producir y caracterizar una harina de mazorca de maíz como alternativa de aplicabilidad en la elaboración o enriquecimiento de productos alimenticios. Se realizaron análisis para determinar las propiedades funcionales y la composición proximal. Los valores medios obtenidos fueron: 0,49\% (ácido fítico), 0,03\% (ácido oxálico), 2,36\% (capacidad de retención de agua), 72,82\% (carbohidratos), 1,82\% (cenizas), 8,91\% (fibras), 5,0\% (índice de absorción de agua), 1,32 \% (lípidos), 6,37\% (potencial de hidrógeno), 2,37 \% (proteínas) y 4,36 \% (humedad). Los resultados físico-químicos de la harina de mazorca de maíz muestran bajo valor de humedad, altos valores de fibra y cenizas cuando se compara con harinas convencionales como trigo, maíz y yuca, en esta perspectiva esta harina puede tener potencial inocuidad en el consumo humano. En cuanto al proceso de producción de harina de mazorca de maíz, los resultados microbiológicos cumplieron con la legislación vigente, demostrando idoneidad para el consumo. La harina de mazorca de maíz producida y analizada tiene un gran prisma para ser incorporada o utilizada para enriquecer alimentos, ya que aporta un beneficio fisiológico por su contenido de fibra y bajos niveles de Ácidos Oxálico y Fítico, además de minimizar y mitigar los impactos de eliminación inadecuada si se desecha en el medio ambiente sin un manejo adecuado.

Palabras clave: Agroindustrial; Residuos, Fibras; Reutilización; Sustentabilidad.

\section{Introdução}

A produção brasileira de milho estimada para 2021 será de 195 milhões de toneladas de grãos, em uma área mínima de 50,7 milhões de hectares (Oliveira et al., 2020). O Brasil ocupa a terceira posição no ranking de produção mundial de milho, sendo que o beneficiamento de cada tonelada de milho processado gera $180 \mathrm{~kg}$ de sabugo o que pode ocasionar um impacto ambiental quando descartado inadequadamente (Souza et al., 2019).

O milho se destaca como uma das fontes econômicas, de produtos diretos, fornecedora de diversos produtos industrializados, entretanto milhares de toneladas de sabugo do milho permanecem sem utilização, pois não tem uso direto na classe de resíduos agrícolas e são consideradas como desperdícios agrícolas nos campos e nas fábricas (Oliveira et al., 2020; 
Macêdo-Júnior, 2013). Segundo Souza et al., (2019), os resíduos sólidos agrícolas produzidos durante o processamento agropecuário são classificados como orgânico e precisam ter um descarte ambientalmente apropriado. Gaspar et. al. (2020) e Cardoso, et al. (2015) afirmam que, os resíduos impactam o meio ambiente com odor desagradável e contaminação dos rios e lençóis freáticos pelo chorume produzido pelos resíduos orgânicos agrícolas.

As indústrias de alimentos ocupam o segundo lugar em impacto ambiental, pois geram grandes quantidades de resíduos orgânicos (Gaspar et al., 2020; Alkozai \& Alam, 2018). Com tanto desperdício sendo descartado vem a preocupação ambiental e como seria possível reaproveitar esse desperdício, pois um dos problemas atuais da agricultura e do agronegócio é a preocupação com a geração de resíduos e sua posterior destinação ou tratamento (Oliveira et al., 2020). Neste sentido, os princípios do desenvolvimento sustentável devem ser lembrados quando da produção agrícola, contribuindo para que esta atividade seja socialmente justa, economicamente viável e ambientalmente correta (Cardoso \&Vieira, 2019). Deste modo, tecnologias devem ser criadas e investidas para que se reduza a quantidade de alimentos que são desperdiçados todos os dias (Cardoso \& Vieira, 2019).

Segundo Macêdo-Júnior (2013), o sabugo de milho pode ser caracterizado intermédio de análises físicos-químicos como: granulometria, massa especifica, densidade, cinzas, proteína, amido, gordura e umidade. Onde, o mesmo é constituído basicamente por: hemicelulose $(34,7 \%)$, celulose $(31,7 \%)$ e lignina $(20,3 \%)$, sendo o restante do percentual composto por Proteínas, Açúcares simples, Lipídeos, amido, água, hidrocarbonetos dentre outros (Souza et al., 2019). O seu baixo custo favorece a produção de alimento acessível, proporcionando à população acesso a alimentos baratos e com alto valor nutritivo (Sousa, 2020).

O direcionamento do setor alimentício em inovar apresentando alimentos diferenciados inexplorados e a aceitação dos consumidores, torna a farinha de sabugo de milho uma matéria-prima que poderá agregar alto valor comercial (Ziglio et al., 2007). Em regiões onde há indisponibilidade ou pouco derivados de trigo para suprir as necessidades da população, a inclusão de farinhas diferenciadas à alimentação apresenta uma alternativa válida, entre tanto esse produto deve possuir uma boa qualidade nutricional para ser oferecida aos consumidores (Ferreira, 2014). O aproveitamento parcial ou integral da farinha do sabugo de milho é uma alternativa que pode colaborar para melhor a ingestão de nutrientes, combate à desnutrição e fome da população (Gaspar et al., 2020). Rica em fibras, a farinha sabugo de milho também é fonte de nutrientes e sais minerais podendo ser utilizada como substituta parcialmente ou completa da farinha de trigo em receitas tradicionais no preparo de bolos, biscoitos e pizzas etc. (Ferreira et al., 2020; Gaspar et al., 2020; Santos, 2018; Ferreira, 2014). A utilização da farinha do sabugo de milho no uso doméstico, bem como sua incorporação na elaboração de produtos industrializados, pode contribuir substancialmente para aumentar a disponibilidade de proteínas, fibras e minerais (Ferreira et al., 2020).

Os antinutrientes são substâncias que restringem a biodisponibilidade dos minerais e vitaminas durante as atividades bioquímicas. Dentre estes, destacam-se: oxalatos, saponinas, ácido fítico, taninos, inibidores de tripsina e nitrato (Pinheiro et. al., 2021). O ácido fítico e o ácido oxálico estão presentes em diversos alimentos de origem vegetal e quando consumidos, impactam negativamente os minerais essenciais para o organismo e causar lesões graves a longo prazo (Pinheiro et al., 2021). A disponibilidade dos minerais no organismo é impactada pelos ácidos fítico e oxálicos, pois essas substâncias têm a capacidade de complexar ou quelar os minerais no organismo, tornando-os insolúveis e provocando a diminuição dos minerais disponíveis para o organismo (Pinheiro et. al., 2021). O ácido fítico ao ligar-se com substâncias metálicas se torna insolúvel, e o oxalato é um íon que se encontra nos vegetais e nos alimentos industrializados e tem complexa capacidade de ligar -se ao cálcio, no qual é pouco solúvel na urina, formando o cálculo renal (Souza Neto, 2017).

Segundo Araújo et al. (2016), a alta concentração de ácidos fítico e oxálico em farinhas podem afetar a biodisponibilidade de proteínas, cálcio, zinco, ferro, magnésio e ocasionar precipitação do cálcio, tornando inviável o consumo 
de farinha. Os autores destacam a importância do monitoramento dos produtos alimentícios enriquecidos com esses resíduos que possuem este perfil.

Nesse sentido o presente estudo teve como objetivo produzir e caracterizar uma farinha de sabugo de milho como alternativa de aplicabilidade no preparo ou enriquecimento de produtos alimentícios.

\section{Metodologia}

O estudo foi realizado nos laboratórios de Analise de Alimentos, Microbiologia e Unidade de Processamento de Frutas e Hortaliças do Curso Superior de Tecnologia em Alimentos do Instituto Federal de Educação, Ciência e Tecnologia do Tocantins IFTO do Campus Paraíso, na Cidade de Paraíso do Tocantins, no estado do Tocantins, Brasil, tendo as coordenadas geográficas $10^{\circ} 10^{\prime} 34^{\prime \prime}$ sul e $48^{\circ} 52^{\prime} 00^{\prime \prime}$ oeste no ano de 2021.

\subsection{Amostras}

As amostras de espigas de milho foram adquiridas no mês de maio de 2021, na feira coberta localizada na cidade de Paraíso do Tocantins TO. Foram selecionadas 30 espigas $(8,980 \mathrm{Kg})$ de milho verde uniformes, sem injúrias e de boa aparência. As espigas de milho selecionadas foram conduzidas imediatamente, em caixas herméticas refrigeradas $\left(4^{\circ} \mathrm{C}\right)$, para o IFTO campus Paraíso do Tocantins.

\subsection{Obtenção da Farinha de Sabugo de Milho}

Na unidade de Processamento de frutas e hortaliças do IFTO, houve a retirada das palhas das espigas. Após a retirada dos grãos de milho (debulhação manual), pesou-se os sabugos, totalizando 2,707 Kg. Os sabugos foram lavados com água corrente e sanitizados com solução de hipoclorito a 200 ppm (parte por milhão), por 30 minutos. Após a sanitização os sabugos foram lavados com água corrente e mantido em repouso por 1 hora em ambiente seco e arejado para remoção do excesso de água da lavagem.

Os sabugos foram fatiados em fatias de 0,5 centímetros de espessura e submetidos a secagem em estufa de circulação de ar a temperatura de $50^{\circ} \mathrm{C}$ por 36 horas. Após a secagem realizou-se a trituração das fatias de sabugo de milho em um moinho de facas.

Foi realizada uma tamisação com abertura de malha de $0,5 \mathrm{~mm}$ para a uniformização das partículas da farinha do sabugo de milho. A farinha de sabugo de milho produzida totalizou 1,029 Kg. A produção da farinha do sabugo de milho (FSM) está representada no fluxograma sabugo da Figura 1. 
Figura 1. Fluxograma da produção da farinha de sabugo de milho.

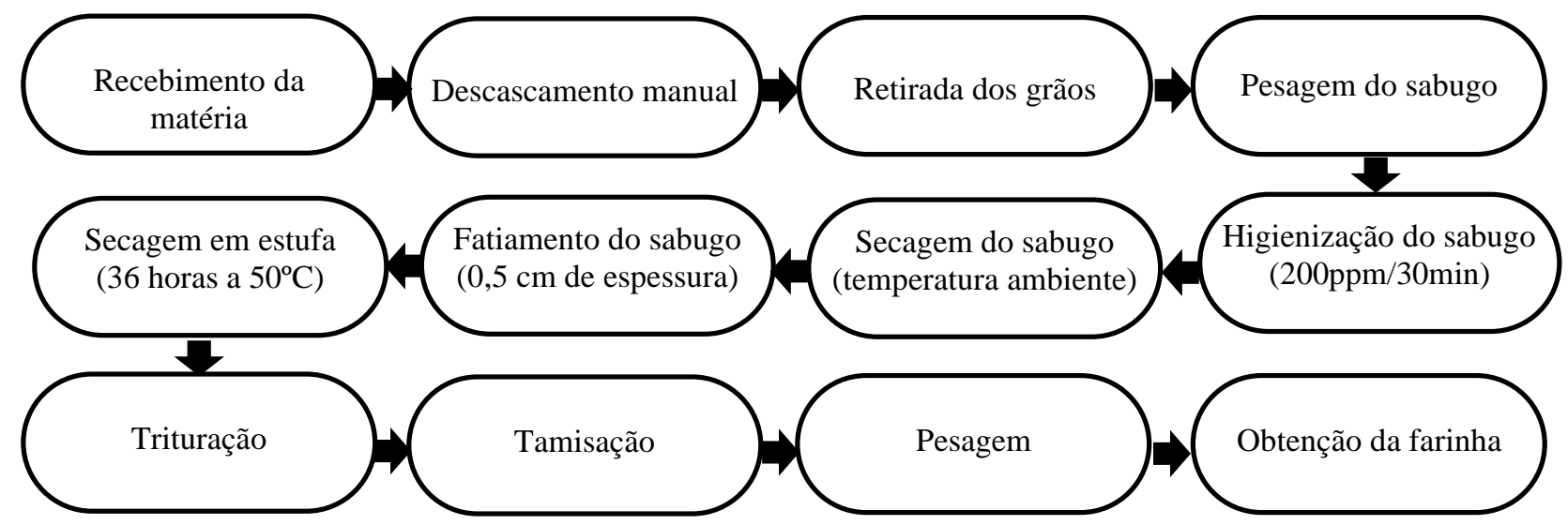

Fonte: Autores.

\subsection{Caracterização da farinha de sabugo de milho}

As análises físico-químicas de cinzas, fibras, lipídios, potencial hidrogeniônico, proteínas e umidade foram realizadas em triplicada no Laboratório de Alimentos do IFTO/Campus Paraíso e seguiram os procedimentos metodológicos abaixo onde:

- Cinzas: determinadas pela calcinação em mufla a $550{ }^{\circ} \mathrm{C}$ por 6 horas, conforme o Instituto Adolfo Lutz-IAL (2008);

- Fibra bruta: apontada pelo ataque ácido-base e quantificadas por gravimetria (IAL, 2008);

- Lipídios: quantificados pela extração direta em Soxhlet (IAL, 2008);

- Potencial hidrogeniônico (pH): por leitura direta com utilização de potenciômetro digital (IAL, 2008);

- Proteínas: realizadas pela técnica de Kjeldahl e o fator de 6,25 para conversão em proteína pela determinação do nitrogênio total (IAL, 2008);

- Umidade: aferida pela perda de dessecação (umidade), e determinada por secagem direta em estufa a $105^{\circ} \mathrm{C}$ (IAL, 2008);

- Carboidratos: determinado por diferença conforme a equação: \% de carboidrato total $=[100-($ cinzas + lipídios + proteínas + fibras + umidade)] (IAL, 2008);

- Ácido Fítico: realizada através do método desenvolvido Lata \& Eskin (1980). A extração e preparo da amostra foi executado de acordo com a procedimento metodológico de Silva et al. (2007). O ácido fítico foi quantificado na forma de fitato através da espectrofotometria UVvis no comprimento de onda de máxima absorção $490 \mathrm{~nm}$. Foi obtida uma curva analítica usando solução de ácido fítico;

- Ácido oxálico: efetivada por Oliveira et al. (2017), onde o oxalato é quantificado por meio da titulação precipitação com permanganato de potássio $0,01 \mathrm{~N}$.

\subsection{Propriedade funcionais da farinha do sabugo de milho}

\subsubsection{Capacidade de retenção de água (CRA)}

A determinação da capacidade de retenção de água (CRA) segui os procedimentos metodológicos de Ferreira (2014), onde foi determinada como a máxima quantidade de água que 1 grama de material pode absorver e manter após centrifugação em baixa velocidade. Foram pesados 5 gramas de amostra em um tubo de centrífuga de $50 \mathrm{~mL}$ previamente pesado. Cerca de $30 \mathrm{~mL}$ de água destilada foram adicionados para completa hidratação. Os tubos com as amostras hidratadas foram submetidos à uma agitação para homogeneização total. 
Em seguida, os tubos foram levados para uma centrifuga e permaneceram por 10 minutos a uma rotação de 2000 rpm (rotações por minuto). O sobrenadante foi descartado e otubo novamente pesado. A CRA foi quantificada através da equação: $C R A=[$ (peso do tubo + sedimento $)-($ peso do tubo + peso da amostra $)] /$ (peso da amostra $)$ e expressa em gramas de água/gramas de sólido.

\subsection{2 Índice de Absorção de Água (IAA)}

O (IAA) foi determinado segundo procedimento metodológico utilizado por Ferreira (2014). Em um tubo de centrífuga, previamente tarado, foram colocados $2,5 \mathrm{~g}$ de amostra e $30 \mathrm{~mL}$ de água. Os tubos foram agitados por 30 minutos em agitador mecânico e, em seguida, centrifugados a $4000 \mathrm{rpm}$ por 10 minutos.

O líquido sobrenadante foi transferido, cuidadosamente, para cápsula, de alumínio, previamente tarada e levada para estufa a $105^{\circ} \mathrm{C}$ por 12 horas. $\mathrm{O}$ gel remanescente foi pesado e o IAA foi calculado conforme a equação: IAA= [peso do resíduo da centrifugação]/ [(peso da amostra base seca) - (peso do resíduo da evaporação)].

\subsection{Analises microbiológicas}

As análises microbiológicas Bacillus Cereus, coliformes a $45^{\circ} \mathrm{C}$ e Salmonella sp foram realizadas em triplicada no Laboratório de Microbiológicas do IFTO/Campus Paraíso, seguindo os procedimentos metodológicos Manual de métodos de análise Microbiológica de Alimentos e Águas (Silva et al., 2010) e os resultados comparados com a Instrução Normativa ${ }^{\circ}$ 60/2019 da Agência Nacional de Vigilância Sanitária-ANVISA (2019).

\subsection{Analise estatística}

Os resultados das análises físico-químicas foram submetidos à análise de variância (ANOVA). E para verificar se houve diferença significativa nos dados, foi aplicado os testes de médias $t$, Tukey ao nível de $5 \%$ de significância nas variáveis no programa SISVAR versão 5.6 (Ferreira, 2019).

\section{Resultados e Discussão}

Os valores médios obtidos na determinação da análise físico químicas realizadas na farinha de sabugo de milho (Tabela 1), comparativo da composição centesimal da farinha de sabugo de milho experimental e a farinha de sabugo de produzida e analisadas por outros autores (Tabela 2), comparativo entre a composição centesimal da farinha de sabugo de milho e farinhas convencionais. (Tabela 3) e as analises microbiológicas (Tabela 4).

Tabela 1. Caracterização físico química da farinha de sabugo de milho.

\begin{tabular}{cc}
\hline Paramentos (\%) & Farinha de sabugo de milho \\
\hline Ácido Fítico & $0,49 \pm 0,01$ \\
Ácido Oxálico & $0,03 \pm 0,01$ \\
Capacidade de retenção de água & $2,36 \pm 0,02$ \\
Carboidratos & $72,82 \pm 0,05$ \\
Cinzas & $1,82 \pm 0,04$ \\
Fibras & $8,91 \pm 0,03$ \\
Índice de absorção de água & $5,04 \pm 0,05$ \\
Lipídios & $1,32 \pm 0,09$ \\
Potencial hidrogeniônico & $6,37 \pm 0,02$ \\
Proteínas & $2,37 \pm 0,08$ \\
Umidade & $4,36 \pm 0,02$ \\
\hline
\end{tabular}

Fonte: Autores. 
A Tabela 1 apresenta os resultados dos parâmetros físico químicos e centesimal realizadas na farinha de sabugo de milho.

Tabela 2. Comparativo da composição centesimal da farinha de sabugo de milho experimental e a farinha de sabugo de produzida e analisadas na literatura.

\begin{tabular}{lcccc}
\hline Paramentos (\%) & Farinha de sabugo de milho & Ferreira (2014) & Ziglio et. al. (2007) & Araujo et. al. (2016) \\
\hline Carboidratos & $72,82 \pm 0,05^{\mathrm{A}}$ & $* \mathrm{ND}$ & $* \mathrm{ND}$ & $70,54 \pm 0,20^{\mathrm{B}}$ \\
Cinzas & $1,82 \pm 0,04^{\mathrm{A}}$ & $0,81 \pm 0,06^{\mathrm{B}}$ & $2,30^{\mathrm{C}}$ & $1,80 \pm 0,00^{\mathrm{D}}$ \\
Fibras & $8,91 \pm 0,03^{\mathrm{A}}$ & $95,1 \pm 0,58^{\mathrm{B}}$ & $32,20^{\mathrm{C}}$ & $18,08 \pm 0,18^{\mathrm{D}}$ \\
Lipídios & $1,32 \pm 0,09^{\mathrm{A}}$ & $0,26 \pm 0,05^{\mathrm{B}}$ & $* \mathrm{ND}$ & $1,75 \pm 0,00^{\mathrm{C}}$ \\
Proteínas & $2,37 \pm 0,08^{\mathrm{A}}$ & $2,02 \pm 0,14^{\mathrm{B}}$ & $2,50^{\mathrm{C}}$ & $4,16 \pm 0,30^{\mathrm{D}}$ \\
Umidade & $4,36 \pm 0,02^{\mathrm{A}}$ & $4,68 \pm 0,09^{\mathrm{B}}$ & $8,90^{\mathrm{C}}$ & $3,68 \pm 0,11^{\mathrm{D}}$ \\
\hline
\end{tabular}

*ND - Não Declarado. Médias com letras diferentes na coluna significam que as farinhas de sabugo de milho diferiram entre si pelo teste de Tukey $(\mathrm{p}<$ 0,05). Fonte: Autores.

A Tabela 2 informa as composições centesimais entre as farinhas de sabugo de milho produzida e as farinhas de sabugo de milho encontras na literatura.

Tabela 3. Comparativo entre a composição centesimal da farinha de sabugo de milho e farinhas convencionais.

\begin{tabular}{lcccccc}
\hline \multicolumn{1}{c}{ Parâmetros (\%) } & Carboidratos & Cinzas & Fibra bruta & Lipídios & Proteínas & Umidade \\
\hline Farinha de Sabugo de milho & $72,82^{\mathrm{A}}$ & $1,82^{\mathrm{A}}$ & $8,91^{\mathrm{A}}$ & $1,22^{\mathrm{A}}$ & $2,37^{\mathrm{A}}$ & $4,36^{\mathrm{A}}$ \\
Farinha de trigo* & $75,10^{\mathrm{B}}$ & $0,80^{\mathrm{B}}$ & $2,30^{\mathrm{B}}$ & $1,40^{\mathrm{B}}$ & $9,80^{\mathrm{B}}$ & $13,00^{\mathrm{B}}$ \\
Farinha de mandioca* & $89,20^{\mathrm{C}}$ & $1,00^{\mathrm{C}}$ & $6,50^{\mathrm{C}}$ & $0,30^{\mathrm{C}}$ & $1,20^{\mathrm{C}}$ & $8,30^{\mathrm{C}}$ \\
Farinha de milho* & $79,10^{\mathrm{D}}$ & $0,50^{\mathrm{D}}$ & $5,50^{\mathrm{D}}$ & $1,50^{\mathrm{D}}$ & $7,20^{\mathrm{D}}$ & $11,80^{\mathrm{D}}$ \\
\hline
\end{tabular}

*Núcleo de estudos e pesquisas em alimentação NEPA, (2011). Médias com letras diferentes na coluna significam que as farinhas de sabugo de milho diferiram entre si pelo teste de Tukey $(\mathrm{p}<0,05)$. Fonte: Autores.

A Tabela 4 demostra as composições centesimais da farinha de sabugo de milho produzida e as farinhas convencionais de trigo, mandioca e milho

Tabela 4. Análises microbiológicas da farinha de sabugo de milho.

\begin{tabular}{ccc}
\hline Determinações & Farinha de sabugo de milho & ANVISA (2019) \\
\hline Bacillus cereus $/ \mathrm{g}$ & $1,0 \times 10^{1}$ & $3,0 \times 10^{3}$ \\
Escherichia coli/g & $1,0 \times 10^{1}$ & $1,0 \times 10^{2}$ \\
Salmonella sp/25g & ausente & Ausência em $25 \mathrm{~g}$ \\
\hline
\end{tabular}

Fonte: Autores.

A Tabela 4 informa os valores das análises microbiológicas e o preconizado na legislação vigente.

De acordo com a Tabela 2 , houve diferenças significativas $(\mathrm{p}<0,05)$ entre a farinha de sabugo de milho produzida e analisada no estudo e as farinhas produzidas e analisadas por Ferreira (2014), Ziglio et al. (2007) e Araújo et al. (2016). O manejo no cultivo do milho, clima, solo onde o plantio do milho foi realizado, podem influenciar diretamente o teor dos minerais em produtos de origem vegetal.

Provavelmente. a farinha de sabugo de milho originada de espigas de milho de diferentes regiões do Brasil como: Nordeste Araújo et al. (2016) e Sul Ferreira (2014) e Ziglio et al. (2007) possam ter contribuído para os diferentes significativas dos parâmetros físico químicos analisados.

Em relação ao comparativo com farinhas convencionais (Tabela 3), observou-se que a farinha de sabugo de milho também apresentou diferenças significativas $(\mathrm{p}<0,05)$. Tais diferenças podem estar associadas a culturas diferente, condições de 
manejo, solo, clima e uso do subproduto (sabugo) da planta. Ainda de acordo com a Tabela 3, observa-se que a farinha de sabugo de milho apresentou vantagem quanto ao teor de fibras e cinzas sobre as farinhas de cereais mais comumente consumidas (trigo, milho e mandioca).

Estudos sobre a composição química e microbiológica de farinha de sabugo de milho são escassos na literatura. De acordo com a Tabela 1, teor de antinutrientes (ácido fítico e ácido oxálico) encontrados na farinha de sabugo de milho nesse estudo foram de $0,49 \pm 0,01 \%$ e $0,03 \pm 0,01 \%$ respectivamente. Araújo et al. (2016) realizando determinação de antinutrientes, encontraram $0,51 \pm 0,10 \%$ de ácido fítico e $0,02 \pm 0,0 \%$ para o ácido oxálico em farinha de sabugo de milho. Esses valores são considerados baixos quando comparado com os valores de 2,01 $\pm 0,27 \mathrm{~g} / 100 \mathrm{~g}$ de ácido fítico encontrado por Nappi et al. (2006) ao determinar os teores de ácido fítico em multimisturas distribuídas em Belo Horizonte e 380,10 mg/100g encontrado por Lopes et al. (2009) em estudo utilizando farinha de quinoa. Segundo Araújo et al, (2016) e Helbig et al. (2008), o ácido fítico produz complexos com minerais no alimento in natura e intestino limitando a disponibilidade dos nutrientes e assim desenvolvendo uma ação antinutricional.

Ainda segundo os autores, o ácido oxálico diminui a biodisponibilidade do cálcio e provocar lesões nos órgãos excretores devido a precipitação da grande concentração de oxalato de cálcio. Não existem um parâmetro na legislação para determinação de ácido fítico e oxálico para farinhas de sabugo de milho.

Em relação a CRA, foi encontrado um valor médio de 2,36 \pm 0,01\% (Tabela 1). Esse valor se aproxima do 2,56 \pm 0,02\% encontrado por Ferreira (2014), e ao realizar CRA em sabugo de milho e estão abaixo dos valores encontrados por Cordeiro (2011) ao analisar a CRA em farinhas de outros tipos de cereais centeio 6,52 $\pm 0,21 \%$, trigo integral 5,45 $\pm 0,03 \%$, aveia $5,33 \pm 0,07 \%$, arroz Integral 7,27 $\pm 0,34 \%$, cevada $4,18 \pm 0,06 \%$, linhaça $3,63 \pm 0,18 \%$ e quinoa negra $2,9 \pm 0,05 \%$.

Segundo Ferreira (2014), a capacidade de retenção de água pode estar relacionada a variação das partículas da farinha durante o processo de moagem dos sabugos de milho e farinha que apresentam baixa quantidade de amido. Huber, (2012) e Ferreira (2014), afirmaram que as propriedades de hidratação em água diminuem com a redução do tamanho da partícula, pois o processo de redução do tamanho das partículas propicia a desintegração da estrutura da matriz fibrosa, expandindo a área superficial e propiciando os grupos polares com sítios ligantes interagir com a água da vizinhança, com redução de absorção de água pela fibra.

Cordeiro, (2011) afirma que os grânulos de amido danificados na farinha, farelo ou flocos tem sua superfície de contato, constituintes e os sítios de ligação aumentados. Esse aumento proporciona o maior número de interações ligações de hidrogênio com moléculas de água disponíveis, gerando consequentemente massa final com maior umidade.

O IAA nesse estudo foi de 5,04 $\pm 0,05 \%$ (Tabela 1). Ferreira (2014) obteve o IAA para farinha de sabugo de milho igual 4,03 $\pm 0,06$, sendo esse valor superior ao encontrado no presente estudo. Segundo Santana et al. (2017), o IAA avalia a adição da farinha em embutidos cárneos, produtos panificados (pães, bolos, etc.) possibilitando a inclusão de água e promovendo a facilidade da manipulação da massa impossibilitando ressecamento no período de armazenamento. As farinhas de frutas e vegetais ricos em fibra que apresentam níveis superiores a 20\%, são considerados como valor padrão para o IAA e consequentemente valores baixos de IAA implica em fraca ligação entre a agua e a farinha que a água. Ainda, este índice relaciona-se com a disponibilidade de grupos hidrofílicos em estabelecer ligações com a água e formação de gel das moléculas de amido.

O percentual de carboidratos apresentado na farinha de sabugo de milho nesse estudo foi de 72,82 $\pm 0,05 \%$ (Tabela 1). Esse valor é superior ao 70,54 $\pm 0,20 \%$ encontrado por Araújo et al. (2016) na análise de carboidrato da farinha de sabugo de milho (Tabela 2). 
Ao realizar um comparativo do teor de carboidratos com outras farinhas convencionais trigo, milho e mandioca), observou-se que a farinha de sabugo de milho apresentou resultados inferior às principais farinhas de cereais mais comumente consumidas (Tabela 3).

$\mathrm{O}$ teor de cinzas encontrado neste trabalho (Tabela 1) para farinha de sabugo de milho foi de 1,82 ( $\pm 0,04 \%)$. Esse resultado está acima de 0,81 ( \pm 0,06\%) encontrado por Ferreira (2014), 1,80 $( \pm 0,00 \%)$ encontrado por Araújo et al. (2016) e abaixo de 2,30\% encontrado por Ziglio et al. (2007) (Tabela 2).

Vieira et al., (2012) determinaram o teor de 2,14\% de cinzas em farinha de sabugo de milho cozido e de 1,69\% em farinha de sabugo de milho verde in natura. $\mathrm{O}$ teor de cinza da farinha de sabugo de milho obtido no estudo realizado foi maior do que os encontrados nas farinhas trigo, milho e mandioca (Tabela 3). Segundo Ferreira (2014), essa variação pode ter ocorrido devido ao cultivar de milho, ao processo de plantio, solo e adubagem.

O teor de fibras de farinha de sabugo de milho apresentado nesse estudo foi de $8,91 \%$ (Tabela 1), sendo menor do que os encontrados por Ferreira (2014), Ziglio et al. (2007) e Araújo et al. (2016) (Tabela 2) e superiores dos que foram encontrados nas farinhas convencionais (Tabela 3), sendo considerados fontes ricas de fibras devem apresentar teor maior que $60 \%$ de fibra total (base seca) em sua composição (Figuerola et al., 2005).

Segundo Ferreira (2014) a adição da farinha do sabugo de milho em produtos cárneos não comprometeria a composição centesimal de uma formulação em comparação com uma tradicional (sem adição de fibras) pois, a contribuição da adição destes ingredientes seria a quantidade de fibra alimentar do produto cárneo.

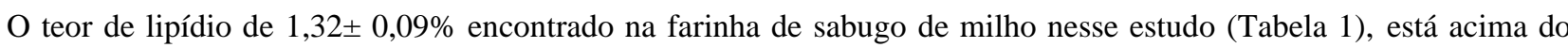
$0,26 \pm 0,05 \%$ encontrado por Ferreira (2014) e abaixo do 1,75 $( \pm 0,00)$ encontrado por Araujo et al. (2016) conforme Tabela 2. O comparativo do teor de lipídios encontrado nesse estudo com outras farinhas convencionais comumente consumidas, apresentou resultados inferior a farinha de milho e superiores as farinhas de trigo e mandioca (Tabela 3). Segundo Ferreira (2014) o baixo valor de lipídios encontrado no estudo em relação a farinha de milho (Tabela 3) se deve ao fato da maturação da espiga de milho, onde ocorre a diminuição do teor de lipídios e aumento da quantidade de açúcar.

$\mathrm{O} \mathrm{pH}$ da farinha de sabugo de milho apresentou valor de $6,37( \pm 0,02)$, este valor foi superior a 5,63 $( \pm 0,15)$ encontrado na farinha de sabugo de milho por Ferreira (2014) e inferior ao pH 7,0 encontrado por Ziglio et al., (2007) para farinha de sabugo de milho verde. Este parâmetro físico químico pode ser um indicador de decomposição do alimento pela infestação e multiplicação de microrganismos.

Segundo Ferreira (2014), o pH apresenta-se como parâmetro físico químico importante seletor da existência microbiana, da ocorrência de interações químicas, determinação dos tratamentos industriais e influência no período de conservação, bem como sobre influências da variedade, região e método de cultivo.

A farinha de sabugo de milho avaliada neste estudo apresentou teor proteico maior do que o encontrado por Ferreira (2014) e Ziglio et al. (2007) e menor do que o resultado encontrado por Araújo et al. (2016) que também avaliaram proteínas em farinhas de sabugo de milho (Tabela 2).

Em comparação com as farinhas convencionais, o teor proteico da farinha de sabugo de milho foi maior do que a farinhas de mandioca e menor do que as farinhas de milho e trigo (Tabela 3). Segundo Ferreira (2014), o valor proteico pode estrar relacionado ao tratamento de lavagem dos sabugos, que possibilitaram uma baixa remoção de proteínas e maior concentração da proteína nos grãos de milho e menor teor no sabugo.

A farinha do sabugo de milho analisada nesse estudo apresentou 4,36\% umidade (Tabela 1). Segundo Ferreira (2014), esse resultado pode ter relação com a procedência da matéria-prima, com baixa umidade, exposta a secagem natural durante a estocagem, além do processo de secagem das fatias do sabugo de milho em ambientes com temperaturas controlados. 
Valores do teor de umidade para farinha de sabugo de milho, acima do encontrado nessa pesquisa, foram determinados por Kuan e Liong (2008), 5,90 \%, Vieira et al., (2012) determinaram 8,19 \% para farinha do sabugo de milho verde in natura, 7,65 \% para farinha do sabugo de milho maduro in natura e 6,74 \% para farinha do sabugo de milho cozido.

O resultado para umidade neste estudo diferiu do obtido por Ferreira (2014), Ziglio et al. (2007) e Araújo et al., (2016), demostrados na Tabela 3, que também investigaram a farinha do sabugo de milho. Provavelmente os fatores tempo e temperatura moderados utilizados pelos pesquisadores para o processo de desidratação dos sabugos podem ter influenciado nesta diferença dos resultados.

Os resultados apresentados, na Tabela 4, das análises microbiológicas da farinha de sabugo de milho atenderam aos padrões microbiológicos exigidos Instrução Normativa n 60/2019 (ANVISA, 2019).

\section{Conclusão}

Os resultados físico-químicos da farinha do sabugo de milho demostram baixo valor para umidade alto valores de fibra e cinzas em relação as farinhas convencionais de trigo, milho e mandioca, podendo garantir segurança no consumo e estabilidade microbiológica.

Quanto ao processo de produção da farinha do sabugo de milho, os resultados microbiológicos atenderam a legislação vigente demostrando aptidão para o consumo. A farinha de sabugo de milho produzida e analisada tem grande potencial para ser incorporada ou utilizada para enriquecer alimentos, pois contribui para um benefício fisiológico devido ao seu teor de fibras e baixos teores de ácidos oxálicos e fítico.

Sugere-se novos estudos sobre a existência de outras substâncias antinutricionais e a verificação da influência da sazonalidade nos parâmetros físico químicas, centesimal, microbiológicas e funcionais da farinha produzida com sabugo de milho.

\section{Agradecimentos}

A Deus, ao Instituto Federal de Educação, Ciência e Tecnologia do Tocantins (IFTO) campus Paraíso do Tocantins

\section{Referências}

Alkozai, A. \& Alam, S. (2018). Utilization of Fruits and Vegetable Waste in Cereal Based Food (Cookies). International Journal of Engineering Research \& Technology, 7(7), 383-390. https://www.ijert.org/utilization-of-fruits-and-vegetable-waste-in-cereal-based-food-cookies

Agência Nacional de Vigilância Sanitária-ANVISA. (2019). Instrução Normativa $n^{\circ}$ 60, de 23 de dezembro de 2019. Estabelece as listas de padrões microbiológicos para alimentos. https://www.in.gov.br/en/web/dou/-/instrucao-normativa-n-60-de-23-de-dezembro-de-2019-235332356.

Araújo, F. H. O., Miranda, I. O., Santos, M. V. S., Oliveira, L. C. de., \& Santos, J. C. dos. (2016). Avaliação da aplicabilidade de farinha de sabugo de milho no enriquecimento de produtos alimentícios. Nutrição Brasil, 15(1), 22-29. https://doi.org/10.33233/nb.v15i1.102.

Cardoso, A. M. A. \& Vieira, T. A. (2019). Práticas de redução do desperdício de alimentos: o caso de um projeto social em Santarém, Pará. Multitemas, 24(58), 137-156. https://doi.org/10.20435/multi.v24i58.2515.

Cardoso, F. T., Froés, S. C., Friede, R., Moragas, C. J., Miranda, M. G. \& Avelar, K. E. S. (2015). Aproveitamento integral de alimentos e o seu impacto na saúde. Sustentabilidade em Debate, 6(3), 131-143. http://dx.doi.org/10.18472/SustDeb.v6n3.2015.16105.

Cordeiro, D. (2011). Propriedades tecnológicas e aceitação sensorial de produtos cárneos empanados com alto teor de grãos inteiros, farinhas, farelos e flocos de cereais. Tese (Doutorado) Universidade Estadual de Campinas, Campinas, SP, Brasil.

Ferreira, D. F. (2019). Sisvar: A computer analysis system to fixed effects split plot type designs. Revista Brasileira de Biometria, 37 (4), 529-535. https://doi.org/10.28951/rbb.v37i4.450.

Ferreira, S. F. (2014). Caracterização de produtos cárneos desenvolvidos com adição de farinha do sabugo de milho (Zea mays). Dissertação (Mestrado) Universidade Federal de Santa Maria, Santa Maria, RS, Brasil. https://repositorio.ufsm.br/bitstream/handle/1/5771/FERREIRA\%2c\%20SABRINA\%20FAGUNDES.pdf?sequence=1\&is Allowed=y.

Ferreira, T. A., Rodrigues, R. C., Freitas, R. F., Perez, A. C. \& Lessa, A. C. (2020). Whole foods and reuse of food: Knowing the practices Diamantina, Minas Gerais, Brasil. Research, Society and Development, 9(7), e201973757. https://doi.org/10.33448/rsd-v9i7.3757. 
Figuerola, F., Hurtado, M. L., Estévez, A. M., Chiffelle, I. \& Asenjo, F. (2005). Fibre concentrates from apple pomace and citrus peel as potential fibre sources for food enrichment. Food Chemistry, 91(3), 395-401. https://doi.org/10.1016/j.foodchem.2004.04.036.

Gaspar, P. B., Spoto, H. F., Borges, M. T. M. R. \& Bernardi, M. R. V. (2020). Elaboração de farinhas e biscoitos com resíduos da agroindústria familiar. Brazilian Journal of Development, 6(5), 25488-25506. https://doi.org/10.34117/bjdv6n5-123.

Helbig E., Buchweitz M. R. D. E. \& Gigante D. P. (2008) Análise dos teores de ácidos cianídrico e fítico em suplemento alimentar: multimistura. Revista de Nutrição, 21(3), 323-328. https://doi.org/10.1590/S1415-52732008000300007.

Huber, E. (2012). Desenvolvimento de produtos cárneos reestruturados de frango (hambúrguer e empanado) com adição de fibras vegetais como substitutos totais de gordura. Tese (Doutorado) Universidade Federal de Santa Catarina - UFSC, Florianópolis, SC.

Instituto Adolfo Lutz-IAL. (2018). Métodos físico-químicos para análise de alimentos. IAL.

Macêdo Júnior, R. O. M. (2013). Avaliação de resíduos agro-industriais (sabugo do milho) no tratamento da água produzida. Dissertação de mestrado, Universidade Tiradentes, Aracaju, SE. Brasil. https://mestrados.unit.br/wpcontent/uploads/sites/4/2016/04/AVALIA\%C3\%87\%C3\%83O-DE RES\%C3\%8 DDUOS-AGRO-INDUSTRIAIS-SABUGO-DO-MILHO-NO-TRATAMENTO.pdf.

Kuan, Y. H. \& Liong, M. T. (2008). Chemical and physicochemical characterization of agrowaste fibrous materials and residues. Journal of Agricultural and Food Chemistry, v. 56, 9252-9257.

Latta, M. \& Eskin, M. (1980). A simple and rapid colorimetric method for phytate determination. Journal of Agricultural and Food Chemistry 1980 28(6), 1313-1315. https://doi//10.1021/jf60232a049.

Lopes, C. O, Dessimoni, G. V, Costa, M. S, Vieira, G, \& Pinto, N. A. V. (2009). Aproveitamento, composição nutricional e antinutricional da farinha de quinoa (Chenopodium quinoa). Revista de Nutrição, 20(4), 669-675. http://serv-bib.fcfar.unesp.br/seer/index.php/alimentos/article/view/1265/874

Nappi, G. U., Ribeiro, M. R., Coelho, J. V. \& Jokl, L. (2006). Validação de métodos para determinação dos ácidos fítico e oxálico em multimistura. Ciência Tecnologia Alimentos, 26(4), 811-20. https://doi.org/10.1590/S0101-20612006000400016>.

Núcleo de estudos e pesquisas em alimentação-NEPA. (2011). Tabela brasileira de composição de alimentos. Campinas: UNICAMP. https://www.cfn.org.br/wpcontent/uploads/2017/03/taco_4_edicao_ampliada_e_revisada.pdf.

Oliveira, M. L., Souza, L. G. M. D., Pereira Neto, R. V. \& Lima, J. C. (2020). Obtaining and characterization of a composite with polymer matrix and corn cob waste filler . Research, Society and Development, 9(12), e32791210849. https://doi.org/10.33448/rsd-v9i12.10849.

Oliveira, L. C. S, Kamonsec, D. H. \& Rostelato-Ferreira, S. (2017). Determinação dos teores de ácido oxálico em diferentes dirigentes de tomate. Nutrivisa Revista de Nutrição e Vigilância em Saúde, 4(2), 61-65. http://www.revistanutrivisa.com.br/wp-content/uploads/2019/11/nutrivisa-vol-4-num-2-06.pdf.

Pinheiro, L. S., Massoli, J. K. P., Neres, L. L. F. G. \& Silva, H. S. (2021). Determination of the oxalate content in food and the influence of this ion on the human organism. Research, Society and Development, 10(15), e273101522622.https://doi.org/10.33448/rsd-v10i15.22622

Santana, G. S., Oliveira Filho, J. G. \& Egea, M. B. (2017). Características tecnológicas de farinhas vegetais comerciais. Revista de Agricultura Neotropical, 4(2), 88-95. https://doi.org/10.32404/rean.v4i2.1549.

Santos, R. F. (2018). Aproveitamento de frutas nativas para elaboração de farinhas e incorporação em biscoitos tipo cookies. Dissertação (Mestrado) Universidade Tecnológica Federal do Paraná, Francisco Beltrão, PR, Brasil.

Silva, N., Junqueira, V. C. A., Silveira, N. F. A., Taniwaki, M. H., Santos, R. F. S. \& Gomes, R. A. R. (2010). Manual de métodos de análise Microbiológica de Alimentos é Águas. São Paulo: Varela.

Silva, M. V. L., Santos, E. B. G. N., Oliveira, L. C., Santos, H. C. F. \& Korn, M. (2007). Fitato e fosfato em farinhas de sementes de abóbora. In: Reunião Anual da Sociedade Brasileira de Química. http://sec.sbq.org.br/cdrom/30ra/resumos/T0164-1.pdf.

Souza, E. F. F. S., Souza, E. F. S., Silva, L. D. B., Resende C. G. F. \& Nascentes, A. L. (2019). Avaliação da capacidade adsortiva do sabugo de milho triturado. Brazilian Journal of Development, 2(4), 1174-1190. https://brazilianjournals.com/ojs/index.php/BJAER/article/view/2574.

Sousa, A. P. M., Campos, A. R. N., Macedo, A. D. B., Dantas, D. L., Apolinário, M. O. \& Santana, R. A. C. (2020). Avaliação da qualidade de farináceos de casca de jaca. Brazilian Journal of Animal and Environmental Research, 3(3), 1786-1796. https://doi.org/10.34188/bjaerv3n3-094.

Souza Neto, F. E. D. (2017). Caracterização e avaliação do potencial da quitosana extraída de Cunninghamella elegans na formação de cristais de oxalato de cálcio e atividade antioxidante. Dissertação (Mestrado) Universidade Federal Rural do Semiárido, Mossoró, RN, Brasil. https://repositorio.ufersa.edu.br/bitstre

am/prefix/2203/1/FranciscoESN_DISSERT.pdf.

Vieira, R. C., Antunes, D. P. C. ; Bispo, V. G. \& Barbosa R. Q. (2012). Caracterização físico-química da palha e sabugo de milho. ENTEQUI. $5^{\circ}$ Encontro Nacional de Tecnologia Química. http://www.abq.org.br/entequi/2012/trabalhos/50/50-476-13695.html.

Ziglio, B. R., Bezerra, J. R. M. V., Branco, I. G., Bastos, R., \& Rigo, M. (2007). Elaboração de Pães com Adição de Farinha de Sabugo de Milho. Revista Ciências Exatas e Naturais, 9(1), 115-128. https://revistas.unicentro.br/index.php/RECEN/article/view/30. 